OPEN ACCESS

Edited by:

Luiza Ghila,

University of Bergen, Norway

Reviewed by:

Karim Bouzakri,

Université de Strasbourg, France

Sarah Tersey,

University of Chicago, United States

*Correspondence:

Jidong Cheng

jidongcheng36@hotmail.com

Wen Liu

w2liu@xmu.edu.cn

Wei Wang

wwei19742007@hotmail.com

Specialty section:

This article was submitted to Diabetes: Molecular Mechanisms,

a section of the journal

Frontiers in Endocrinology

Received: 31 October 2020

Accepted: 13 May 2021

Published: 14 June 2021

Citation:

Jiang M, Kuang Z, He Y,

Cao Y, Yu T, Cheng J,

Liu W and Wang W (2021)

SNAPIN Regulates Cell Cycle

Progression to Promote

Pancreatic $\beta$ Cell Growth.

Front. Endocrinol. 12:624309. doi: 10.3389/fendo.2021.624309

\section{SNAPIN Regulates Cell Cycle Progression to Promote Pancreatic $\beta$ Cell Growth}

\author{
Mengxue Jiang ${ }^{1}$, Zhijian Kuang ${ }^{2}$, Yaohui $\mathrm{He}^{2}$, Yin $\mathrm{Cao}^{2}$, Tingyan $\mathrm{Yu}^{1}$, Jidong Cheng ${ }^{1 *}$, \\ Wen Liu $^{2 *}$ and Wei Wang ${ }^{1 *}$ \\ 1 Department of Endocrinology, Xiang'an Hospital of Xiamen University, School of Medicine, Xiamen University, \\ Xiamen, China, ${ }^{2}$ Fujian Provincial KeyLaboratory of Innovative Drug Target Research, School of Pharmaceutical Sciences, \\ Xiamen University, Xiamen, China
}

In diabetes mellitus, death of $\beta$ cell in the pancreas occurs throughout the development of the disease, with loss of insulin production. The maintenance of $\beta$ cell number is essential to maintaining normoglycemia. SNAPIN has been found to regulate insulin secretion, but whether it induces $\beta$ cell proliferation remains to be elucidated. This study aimed to explore the physiological roles of SNAPIN in $\beta$ cell proliferation. SNAPIN expression increases with the age of mice and SNAPIN is down-regulated in diabetes. KEGG pathway and GO analysis showed that SNAPIN- interacting proteins were enriched in cell cycle regulation. B cell cycle was arrested in the S phase, and cell proliferation was inhibited after SNAPIN knockdown. The expression of CDK2, CDK4 and CCND1 proteins in the S phase of the cell cycle were reduced after SNAPIN knockdown, whereas they were increased after overexpression of SNAPIN. In addition, insulin protein and mRNA levels also increased or decreased after SNAPIN knockdown or overexpression, respectively. Conclusions: Our data indicate that SNAPIN mediates $\beta$ cells proliferation and insulin secretion, and provide evidences that SNAPIN might be a pharmacotherapeutic target for diabetes mellitus.

Keywords: SNAPIN, $\beta$ cells, proliferation, cell cycle, diabetes

\section{INTRODUCTION}

Diabetes is a prevalent disease worldwide, and it has become a serious social health problem (1). It ultimately results in a deficiency of functional pancreatic $\beta$ cells (2).The maintenance of $\beta$-cell number and islet mass is essential for maintaining normoglycemia $(3,4)$. Human $\beta$ cell replication rates are very low, and the cells are only capable of replication for a brief period after birth (5).

Type 1 diabetes mellitus (T1DM) is associated with impaired $\beta$ cell mass (6).The pathogenesis of type 2 diabetes is more variable, and it consists of insulin resistance and defective insulin secretion (6). More specifically, type 2 diabetes mellitus (T2DM) is associated with genetic predisposition and environmental factors, such as obesity and diet (7). During pregnancy and the early stages of diabetes, compensatory proliferation of pancreatic $\beta$ cells occurs in response to changes in blood glucose $(8,9)$. Glucose itself is able to stimulate $\beta$ cell replication (10), and several lines of evidence indicate that the terminally differentiated pancreatic $\beta$ cells retain significantly proliferative capacity 
in vivo $(11,12)$. This proliferative capacity has attracted considerable research attention in terms of developing therapeutic strategies for diabetes mellitus. Although a number of studies concerning differentiated $\beta$-like cells from embryonic stem cells or induced pluripotent (adult) stem cells are in progress, the low conversion efficiency of $\beta$ cells from stem cells remains a challenge for developing cell-based therapies (13). Glucokinase signaling, carbohydrate response element-binding protein (ChREBP), nuclear factor of activated T-cells (NFAT), platelet-derived growth factor (PDGF), CDK4/6 and TCF7L2 have all been reported to stimulate human $\beta$ cells proliferation (14-19). Therefore, the mechanisms regulating $\beta$ cell mass have been revealed that underlie the development of T1DM and T2DM, which is important for developing novel therapeutic approaches for diabetes. This proliferative capacity has attracted considerable research attention in terms of developing therapeutic strategies for diabetes mellitus.

SNAPIN is a protein that interacts with SNARE complexes during synaptic transmission and was first reported by Jeffrey $M$. Ilardi in 1999 and it was first identified in neurons and located on synaptic vesicle Membranes (20). It is also a component member of the BLOC-1 complex and BORC complex (21). The BLOC-1 complex is required for normal biogenesis of lysosome-related organelles (LRO), such as platelet-dense granules and melanosomes (22), and the BORC is required for lysosome positioning in mammalian cells (21). Increasing evidence shows that SNAPIN is important for retrograde axonal transport (23), late endosomal-lysosomal trafficking (24), and glucose-induced insulin exocytosis (25). It is also believed to be involved in a variety of signal transduction and intracapsular transport/fusion functions (26).

SNAPIN is specifically expressed in the endocrine department of the pancreas. Diffuse cytoplasmic staining has been observed, and the cells were clustered into punctate structures, which co-located with insulin-secreting granules (27).The insulin secretion may be caused by the interaction between the c-terminal $\mathrm{H} 2$ region of SNAPIN and sn-1 region of snap-25 in the SNARE complex $(27,28)$, which initiates the process of insulin secretion particle targeting, tethering, initiation and membrane fusion $(27,29)$. These exocytosis processes are mediated by the Munc18/SNARE complex (30).

In addition, SNAPIN is a target of protein kinase A (PKA) (31), which is a critical regulator of glucose-stimulated insulin exocytosis in pancreatic $\beta$ cells by promoting the interaction and assembly of insulin secretory vesicle-associated proteins Snap25 and TMEM27 (32). SNAPIN is significantly correlated with the TMEM27 gene, which codes a membrane protein cleaved and shed by pancreatic beta cells that have been proposed as a beta cell mass biomarker (33). This indicates that SNAPIN may also be a biomarker for beta cells. The function of SNAPIN in $\beta$ cell growth is poorly understood, and our findings reveal that the overexpression of SNAPIN in Min6 cells can promote cell proliferation and is promising in achieving the goals of regenerative medicine for diabetes treatment.

\section{MATERIALS AND METHODS}

\section{Cloning Procedures}

Snapin full length was PCR-amplified from cDNAs and cloned at XhoI and BamHI sites of PCDH-3xFlag-3xHA-EF1-puromycin vector. Primers were designed using the Primer Premier 5.0 software (Premier Biosoft International, Palo Alto, CA).

\section{Lentivirus Packaging and Infection}

HEK293T cells were seeded in culture plates for $12 \mathrm{hrs}$ and transfected with lentiviral vectors together with packaging vectors, pMDL, VSVG, and REV, at a ratio of 10:5:3:2 using Lipofectamine 2000 for $48 \mathrm{hrs}$. Virus was collected, filtered and added to $\beta$ cells in the presence of $10 \mu \mathrm{g} / \mathrm{mL}$ polybrene (Sigma, $\mathrm{H} 9268$ ), followed by centrifugation for $30 \mathrm{mins}$ at $1,500 \mathrm{~g}$ at $37^{\circ} \mathrm{C}$. Medium was replaced $12 \mathrm{hrs}$ later. The transduction efficiency was evaluated by immunoblotting analysis.

\section{shRNA Infection}

The packaging process of lentiviruses particles was the same as above. Primers sequences were in the Table 1. The transient transfection of plasmids into the cells was performed by using Lipofactamine 2000 reagents (Invitrogen) according to the manufacturer's instructions.

\section{Cell Lines}

The mouse pancreatic Min6, the rat pancreatic INS1 and the HEK-293T cell lines were obtained from ATCC. Min6 cells were maintained in high-glucose DMEM medium(BI) supplemented with $15 \% \mathrm{v} / \mathrm{v}$ fetal bovine serum (FBS, BI), $50 \mathrm{mmol} / \mathrm{L} \mathrm{2-}$ mercaptoethanol, and $1 \%$ penicillin-streptomycin at $37^{\circ} \mathrm{C}$ and $5 \% \mathrm{CO} 2$ in a humidified atmosphere in an incubator. HEK-293T

TABLE 1 | shRNA targeting sequencing and primers for SNAPIN cloning.

\begin{tabular}{|c|c|c|}
\hline Gene & Forward $\left(5^{\prime} \rightarrow 3^{\prime}\right)$ & Reverse $\left(5^{\prime} \rightarrow 3^{\prime}\right)$ \\
\hline (plko.1) & GAGCACAGTTCTGTAGCTAGGTTGTTITG & TGCTCGAGCACAGTTCTGTAGCTAGGTTG \\
\hline (plko.1) & GAGAGCTAGGTTGTCAATTTGTCTाITG & GCTCTCGAGAGCTAGGTTGTCAATTTGTTC \\
\hline shRNA-1 & TCGACAACCTAGCTACAGAACTGTGTTCAAG & GATC GAAAAAACAACCTAGCTACAGAACT \\
\hline (psicor) & AGACACAGTTCTGTAGCTAGGTTGTIIITC & GTGTCTCTTGAACACAGTTCTGTAGCTAGGTTG \\
\hline shRNA-2 & TCGAGAACAAATTGACAACCTAGCT TTCAA & GATC GAAAAAAGAACAAATTGACAACCTA \\
\hline
\end{tabular}


was cultured in DMEM medium supplemented with $10 \% \mathrm{v} / \mathrm{v}$ fetal bovine serum (FBS, BI) and $1 \%$ penicillin-streptomycin in an incubator at $37^{\circ} \mathrm{C}$ and $5 \% \mathrm{CO} 2$ in a humidified atmosphere in an incubator. The rat pancreatic INS1 cells were cultured in RPMI1640 (Hyclone) containing 10\% v/v fetal bovine serum (FBS, BI), 1\% penicillin-streptomycin 1\% glutamine, $1 \mathrm{mM}$ sodium pyruvate, and $50 \mu \mathrm{M} \beta$-mercaptoethanol (sigma).

\section{Animal}

Male KM mice weighing approximately 18-25 g were purchased from the Animal Center of Xiamen University. Mice were humanely housed at $22 \pm 2^{\circ} \mathrm{C}$ with 12 -h light/dark cycles. All animals had free access to food and water. All animal studies were approved by the ethical review committee of Xiamen University and followed the regulations of the National Institutes of Health guidelines on the care and welfare of laboratory animals. $\mathrm{Db} / \mathrm{Db}$ and HFD mice were obtained from Li Ming Yu lab at Xiamen University.

\section{Immunohistochemistry}

SNAPIN and insulin were analyzed by immunohistochemical staining of frozen sections from adult mouse pancreas fixed $\mathrm{O} /$ $\mathrm{N}$ in $4 \%$ PFA in PBS at RT, pH 7.4, cryoprotected in 30\% sucrose in PBS, embedded in Tissue-Tek (Sakura; Værlose, Denmark), and cut into $9-\mu \mathrm{m}$ sections on a Leica cryostat. Antigen retrieval was performed by microwave treatment for 4 mins at $600 \mathrm{~W}$ in $200 \mathrm{~mL} 0.01 \mathrm{M}$ citrate buffer, followed by 15 mins at $250 \mathrm{~W}$, and finally left to cool for 20 mins. Tissue sections were rinsed in TBS, quenched in 3\% $\mathrm{H} 2 \mathrm{O} 2$ for 5 mins, and rinsed again. Then, 10\% goat serum was used for blocking for $1 \mathrm{hr}$ before overnight incubation with the purified rabbit anti-SNAPIN antibodies diluted 1:200 and rabbit anti-insulin antibodies diluted 1:400 in 10\% goat serum blocking buffer. Sections were washed three times for 5 mins each in TBS between incubations with primary antibody and the following incubations with biotinylated secondary antibody (Zymed; Aarhus, Denmark) for 30 mins. Bound antibodies were visualized with the $\mathrm{DAB}$ after a 3 mins incubation period and a subsequent wash in TBS, and the slides were counterstained with hematoxylin. Images were collected with an Olympus (Tokyo, Japan) BX51 microscope and captured using a chilled Hamamatsu C5810 CCD camera (Hamamatsu City, Japan) and Image Pro Plus 4.5 software.

\section{Nuclear Extraction of Cells}

SNAPIN was overexpressed in Min6 cells. All steps were performed on ice with ice-cold reagents in pre-centrifuge tubes. We first used ice-cold 1xPBS to wash cells and scrape cells gently into a $15 \mathrm{~mL}$ tube. They were centrifuged for 5 mins at $500 \mathrm{rpm}, 4^{\circ} \mathrm{C}$. Then the pellet was resuspended in $1 \mathrm{~mL}$ ice cold BUFFER1 (1 M HEPES, PH 8.0, $1 \mathrm{M} \mathrm{Mgcl} 2,1 \mathrm{M} \mathrm{KCl}$ and $1 \mathrm{M}$ DTT) and incubated for 15 mins on ice to allow cells to swell. $\mathrm{Np} 40$ was added to vortex for $10 \mathrm{~S}$. Cells were centrifuged for 3 mins at maximum speed, then supernatant was aspirated with pipet, which was the cytoplasmic fraction. The pellet was resuspended in cold BUFFER2 (1 M HEPES, PH 8.0, $1 \mathrm{M}$
Mgcl2, Glycerol, $1 \mathrm{M}$ Nacl, 0.5M EDTA and $1 \mathrm{M}$ DTT), vortexed $30 \mathrm{~S}$ and rotated vigorously at $4^{\circ} \mathrm{C}$ for $30 \mathrm{mins}$. The pellet was centrifuged for 15 mins at maximum speed, and the supernatant was removed and transferred to a fresh, chilled tube. Assay for protein concentration for immunoblotting analysis.

\section{Confocal Immunofluorescence Microscopy}

$\beta$ cells were fixed in $4 \%$ paraformaldehyde for half an hour at room temperature. Then, cells were washed three times with PBS for 5 mins at room temperature. $0.1 \%$ Triton- 100 was added for permeation for 10 mins, and cells were incubated in a blocking buffer (5.0\% BSA in PBS) for $1 \mathrm{hr}$ at room temperature. Then we performed immunostaining using the primary antibodies SNAPIN (1:50) and insulin (1:800) incubated overnight at $4^{\circ} \mathrm{C}$, followed by fluorophore-conjugated secondary antibodies. The immunolabeled cells were analyzed with a Carl Zeiss LSM5 EXITER or Leica TCS SP8 STED laser scanning confocal microscope. The green channel was imaged using a 488-nm laser line $(120 \mathrm{~mW} / \mathrm{cm} 2,2.5 \%)$. The red channel was imaged using a 559-nm laser $(120 \mathrm{~mW} / \mathrm{cm} 2,2.0 \%)$. Images were acquired in 4-s intervals (frame time $3.9 \mathrm{~s}$ ). A pulsed $375-\mathrm{nm}$ laser $(10 \mathrm{MHz})$ was applied for uncaging experiments in the entire field of view for eight frames (3.2 s/frame). The dual scanner setup allowed for simultaneous laser stimulation and confocal imaging. This permitted the acquisition of cellular responses that occurred during or immediately after laser stimulation.

\section{Cell Cycle and Flow Cytometry}

Min6 cells that underwent SNAPIN overexpression or knockdown were added to $1 \mathrm{~mL}$ cold PBS to re-suspend cell pellet and vortexed gently and an equal volume of cold absolute ethanol (store at $-20^{\circ} \mathrm{C}$ ) was added dropwisely to cell suspension in the same $15 \mathrm{~mL}$ tube. Then, it was stored at $-20^{\circ} \mathrm{C}$ for at least 2 hrs. Before staining, cells were washed twice with cold PBS and centrifuged at $4^{\circ} \mathrm{C}, 3000 \mathrm{~g}$, for $5 \mathrm{mins}$, and supernatant was completely removed. PI staining solution was added, and it was incubated at $37^{\circ} \mathrm{C}$ for 15 mins. Data were acquired on a flow cytometry. Then, we used PI to stain Min6 cells that transfected shRNA for 15 mins. Cells or nuclei were filtered through 40-mm sieves, and flow cytometry was performed on a 4-laser, LSRII (BD Biosciences). Data were analyzed with FlowJo software.

\section{Cell Proliferation Assay}

Min6 cells that underwent SNAPIN overexpression or knockdown were seeded into a 96-well plate and were incubated with the medium for $24 \mathrm{hrs}$. The cell viability was measured by MTS analysis using CellTiter 96 AQueous One Solution Cell Proliferation Assay (Promega). For the measurement of cell viability, $500 \mu \mathrm{L}$ of medium/MTS solution mix $(20 \mu \mathrm{L} \mathrm{MTS} / \mathrm{mL}$ medium $)$ was added per well. The plate was incubated at $37^{\circ} \mathrm{C}$ for $1 \mathrm{hr}$. Then, the absorbance at $490 \mathrm{~nm}$ was measured using an automatic microplate reader. Cell viability was measured every $24 \mathrm{hrs}$ for consecutive four days. 


\section{Ethynyldeoxyuridine (EdU) Analysis}

Proliferating cells were assessed using a Click-iT ${ }^{\mathrm{TM}}$ EdU Proliferation Assay (Invitrogen) following the manufacturer's protocol. Briefly, Min6 cells that underwent knockdown were inoculated seeded into a 96-well plate (5000 cells/well). Then, 10 um EdU labeling media was added and cells were incubated for 24hrs. $50 \mu \mathrm{L}$ Click-iT ${ }^{\mathrm{TM}}$ EdU fixative was added to each well for 5 mins and $50 \mu \mathrm{L} 1 \mathrm{X}$ Click-iT ${ }^{\mathrm{TM}}$ reaction cocktail to each well for 30 mins. Then, $1.5 \%$ BSA was added to block cells for 5 mins. After washing several times, $100 \mu \mathrm{L}$ Amplex ${ }^{\mathrm{TM}}$ UltraRed reaction mixture was added for 15 mins and followed by incubated with $10 \mu \mathrm{L}$ Amplex ${ }^{\mathrm{TM}}$ UltraRed stop reagent. Fluorescence was measured with excitation maximum of $568 \mathrm{~nm}$ and emission maximum of $585 \mathrm{~nm}$.

\section{Annexin V-FITC/Propidium lodide (PI) Staining}

Apoptosis of $\beta$ cells were measured by Annexin V/FITC(BD Bioscience)according to the manufacturer's protocol. Cells were harvested and resuspended in $100 \mu \mathrm{L}$ binding buffer, followed by staining with $5 \mu \mathrm{L}$ FITC- conjugated Annexin V and $5 \mu \mathrm{L}$ PI in the dark for 15 mins at room temperature. Then, $00 \mu \mathrm{L}$ binding buffer was added to resuspend cells. Cells were detected by flow cytometry (BD Biosciences). In the early stage of apoptosis, cell membranes were stained with FITC- conjugated Annexin V, whereas nuclei were not stained with PI. In the late stage of apoptosis, cells were stained with both FITC- conjugated Annexin V and PI. The results were analyzed by FlowJo vX.0.7 (FlowJo LLC).

\section{Insulin Secretion in bb Cells}

In order to test the secretory response to glucose, Min6 cells were cultured on glass coverslips for $24 \mathrm{hrs}$. After $24 \mathrm{hrs}$ of plating, Min6 cells were incubated for $1 \mathrm{hr}$ at $37^{\circ} \mathrm{C}$ in KIRH BUFFER (136 mmol/L NaCl, $4.7 \mathrm{mmol} / \mathrm{L}$ potassium chloride $(\mathrm{KCl}), 1.2$ $\mathrm{mmol} / \mathrm{L} \mathrm{KH} 2 \mathrm{PO} 4,1.2 \mathrm{mmol} / \mathrm{L} \mathrm{MgSO} 4,5 \mathrm{mmol} / \mathrm{L} \mathrm{NaHCO} 3,1$ $\mathrm{mmol} / \mathrm{L} \mathrm{CaCl} 2,10 \mathrm{mmol} / \mathrm{L}$ HEPES, and 0.5\% BSA, pH 7.4) supplemented with either $2.8 \mathrm{mmol} / \mathrm{L}$ or $16.7 \mathrm{mmol} / \mathrm{L}$ glucose. Insulin was detected by ELISA (wide range mouse insulin immunoassay kit, catalogue number: 32100). $5 \mu \mathrm{L}$ of standard and sample and $100 \mu \mathrm{L}$ detection antibody was added to each well followed by incubation at room temperature for 90 mins. After washing for several times, $100 \mu \mathrm{L}$ of substrate solution was added to each well at room temperature for 15 mins followed by adding $100 \mu \mathrm{L}$ of stop solution and detecting at $450 \mathrm{~nm}$ immediately. Cells were fixed with $4 \%$ paraformaldehyde for 20 mins, and fixed cells were permeabilized with $0.5 \%$ Triton- 100 for 15 mins, treated with $0.1 \%$ Tween 20 in phosphate buffered saline for 5 mins and blocked with 5\% FBS for 40 mins before incubation with the primary antibody against SNAPIN (1:50; proteintech) and insulin (1:800; Cell Signaling Technology) overnight at $4^{\circ} \mathrm{C}$, followed by incubation with rhodaminelabeled anti-mouse IgG secondary antibody (1:200; Chemicon, Temecula, USA) for $1 \mathrm{hr}$ at room temperature. Nuclear localization was counterstained with DAPI.

\section{Tissues and Cells RNA Isolation}

Mouse tissues were isolated from 5 days, 2, 3, 4 and 8 weeks mice. Total RNA was then extracted using TRIzol reagent (Gibco-BRL) and following the manufacturer's instructions.

\section{Real-Time Reverse Transcriptase- Polymerase Chain Reaction}

Briefly, total RNA was extracted using the TRIzol reagent (Invitrogen) and complementary DNA was generated using the PrimeScript ${ }^{\mathrm{TM}}$ reverse transcript reagent Kit (Takara, Tokyo, Japan). From $1 \mu \mathrm{g}$ RNA aliquots, we synthesized cDNA using random hexamers or oligo $(\mathrm{dT})$, and reverse transcriptase, following the manufacturer's protocol. The reactions were run for 40 cycles at $30^{\circ} \mathrm{C}$ for $10 \mathrm{mins}, 42^{\circ} \mathrm{C}$ for $20 \mathrm{mins}, 99^{\circ} \mathrm{C}$ for 5 mins, and $4^{\circ} \mathrm{C}$ for 5 mins using real-time PCR detection system (Bio-Rad, Hercules, USA) according to the manufacturer's instruction and verified on gel. Real-time reverse transcriptasepolymerase chain reactions (real-time RT-PCRs) were performed using the Power SYBR Green PCR Master Mix (Roche) and a 7500 Real-Time PCR Detection System (Applied Biosystems). Actin was used as an internal control. Primer sequences are listed in Table 2 . All experiments were performed in triplicate, and the data are shown as mean \pm SD.

\section{Western Blotting}

Cells were seeded at the appropriate density, and total protein of cells or tissues were using cell lysis buffer containing $(50 \mathrm{mM}$ Tris- $\mathrm{HCl}$ (pH 7.4), $150 \mathrm{mM} \mathrm{NaCl}, 1 \mathrm{mM}$ EDTA and 1\% Triton $\mathrm{X}-100)$ containing protease inhibitor cocktail (sigma, P27141BTL) on ice for 30 mins followed by centrifugation. Protein concentrations was determined with a Bicinchoninic Acid Assay Kit (Beyotime Biotechnology). Protein $(20 \mu \mathrm{g} /$ lane) was separated by $10-15 \%$ sodium dodecyl sulfate-polyacrylamide gel electrophoresis (SDS-PAGE) and transferred onto polyvinylidene fluoride membranes (Millipore, Billerica, MA). The membranes were blocked for $1.5 \mathrm{hrs}$ in Tris-buffered saline and Tween 20 (TBST, pH 7.6) containing 5\% non-fat milk powder at room temperature and incubated with primary

TABLE 2 | Real-time PCR primer sequences.

\begin{tabular}{|c|c|c|}
\hline Gene & Forward $\left(5^{\prime} \rightarrow 3^{\prime}\right)$ & Reverse $\left(5^{\prime} \rightarrow 3^{\prime}\right)$ \\
\hline SNAPIN & AGCTACAGAACTGTGCCGGATCAA & GCTTGGAGAACCAGGAGGGTAAA \\
\hline Insulin1 & AGGACCCACAAGTGGAACAA & GCTGGTAGAGGGAGCAGATG \\
\hline Insulin2 & GGACCCACAAGTGGAACAAC & GTGCAGCACTGATCCACAAT \\
\hline CDK2 & AATGCAGAGGGGTCCATCAA & GGAGTAGTACTTGCAGCCCA \\
\hline Actin & TGTTACCAACTGGGACGACA & GGGGTGTTGAAGGTCTCAAA \\
\hline
\end{tabular}


antibodies at $4^{\circ} \mathrm{C}$ overnight. The membranes were then washed three times with TBST for 15 mins each and incubated with antirabbit secondary antibodies (1:5,000 in TBST) conjugated to HRP for $1 \mathrm{hr}$ at room temperature. The blots were then developed in the dark by using an ECL detection kit (Proteintech). Band intensities were quantified by ImageJ 1.45 software (NIH, USA). Antibodies are listed in Table 3.

\section{Immunoprecipitation Assay}

Two days after transfection, the cells were lysed in lysis buffer (1\% Triton X-100, 50 mM Tris- $\mathrm{HCl}$ (pH 7.4), $150 \mathrm{mM} \mathrm{NaCl}, 1$ mM EDTA, $1 \%$ sodium deoxychlate) with protease inhibitor cocktails. Pre-washed Flag-beads were added. After immunoprecipitation, Flag-Beads were washed 4-5 times with lysis buffer (containing protease inhibitor). Flag peptides were added to elute Flag-tagged proteins. 4xSDS loading buffer was added into the supernatant after enrichment and the sample was boiled in the metal bath for $10 \mathrm{~min}$ before being The elutes were then subjected to SDS-PAGE and Western blotting analysis.

\section{LC-MS Analysis and Database Search}

Each immunoprecipitation (IP) was carried out in triplicate. Min6 cells expressing Flag-SNAPIN or PCDH vector were grown on $15 \mathrm{~cm}$ plates until $90 \%$ confluent and then subjected to IP. The elutes after IP were firstly reduced in $20 \mathrm{mM}$ dithiothreitol (DTT) (Sigma) at $95{ }^{\circ} \mathrm{C}$ for 5 mins, and subsequently alkylated in $50 \mathrm{mM}$ iodoacetamide (IAA) (Sigma) for 30 mins in the dark at room temperature. After alkylation, the samples were transferred to a $10 \mathrm{kD}$ centrifugal spin filter (Millipore) and sequentially washed with $200 \mathrm{~mL}$ of $8 \mathrm{M}$ urea for three times and $200 \mathrm{~mL}$ of $50 \mathrm{mM}$ ammonium bicarbonate for two times by centrifugation at $14,000 \mathrm{~g}$. Next, tryptic digestion was performed by adding trypsin (Promega) at 1:50 (enzyme/substrate, $\mathrm{m} / \mathrm{m}$ ) in $200 \mathrm{~mL}$ of $50 \mathrm{mM}$ ammonium bicarbonate at $37^{\circ} \mathrm{C}$ for $16 \mathrm{hrs}$. Peptides were recovered by transfer-ring the filter to a new collection tube and spinning at 14,000 g. To increase the yield of peptides, the filter

TABLE 3 | Antibodies used in Western blotting, immunohistochemistry and immunofluorescence.

\begin{tabular}{lcll}
\hline Antibody & Dilution & Host Species & Supplier \\
\hline 3-Actin & $1: 1000$ & Rabbit & proteintech \\
Snapin & $1: 1000$ & Rabbit & proteintech \\
Snapin & $1: 1000$ & Rabbit & Synaptic System \\
Insulin & $1: 800$ & mouse & Cell Signaling \\
Insulin & $1: 400$ & Rabbit & proteintech \\
Flag & $1: 1000$ & mouse & Sigma \\
HA & $1: 1000$ & Rabbit & Santa Cruz \\
CDK2 & $1: 1000$ & Rabbit & proteintech \\
CDK4 & $1: 1000$ & Rabbit & proteintech \\
CCND1 & $1: 1000$ & Rabbit & proteintech \\
PARP & $1: 1000$ & Rabbit & Cell Signaling \\
HSP60 & $1: 1000$ & Rabbit & proteintech \\
BLOC1S1 & $1: 1000$ & Rabbit & ABclonal \\
HRP-anti-rabbit IgG & $1: 1000$ & Rabbit & Beyotime \\
CY3-anti-rabbit IgG & $1: 200$ & Rabbit & Beyotime \\
CY3-anti-mouse IgG & $1: 200$ & mouse & Beyotime \\
FITC-anti-mouse IgG & $1: 200$ & mouse & Beyotime \\
& & &
\end{tabular}

was washed twice with $100 \mathrm{~mL}$ of $50 \mathrm{mM}$ ammonium bicarbonate. Peptides were desalted by StageTips $(34,35)$.

GO and KEGG pathway analysis Gene Ontology (GO) is an ontology widely used in the field of bioinformatics for annotating large scale genes and gene products (36). KEGG is a practical database resource for genome sequencing and polymer experiment technology. It is generated by molecular- level information, especially macromolecular datasets, which can be used to predict which by pathways of a particular gene is enriched (37). It covers information resources such as diseases and pathways, GO analysis and KEGG analysis were performed by DAVID tools (https://david.ncifcrf.gov/). P $<0.01$ was considered statistically significant.

\section{Statistical Analysis}

Group data are displayed as means \pm standard errors of the mean (SEMs). Differences between groups were calculated by Student's unpaired two-tailed t-tests or one-way analyses of variance (ANOVAs) followed by Tukey's post hoc tests. $\mathrm{P}<0.05$ was considered statistically significant.

\section{RESULTS}

\section{SNAPIN Expression Increases With the Age of Mice and SNAPIN Is Down- Regulated in Diabetic Mice}

Tissues of six mice of different ages were isolated, followed by protein extraction to detect the expression of SNAPIN (Figures 1A, B). We found that the expression of SNAPIN was relatively higher in liver (38), kidney (39) and pancreas (25). The expression level of SNAPIN in mouse pancreas also closely increased with the age of mice (Figures 1C, D).

We next investigate whether SNAPIN expression has discrepancy in its involvement with healthy and diabetic mice. Hematoxylin staining was performed to detect insulin and SNAPIN expression in wild-type and diabetic mice. Decreased $\beta$ cell masses and decreased SNAPIN were observed in diabetic mice compared with WT controls. Diabetic mice had much less SNAPIN compared with WT controls (Figure 1E), tending to a $40 \%$ reduction. We also investigated SNAPIN expression by immunostaining, and diabetes mice had much less SNAPIN compared with WT controls (Figures 1F, G).

\section{SNAPIN Is Mostly Located in the Cytoplasm, and Is Co-Located With Insulin Secretory Granules}

SNAPIN was originally reported in the neurons and exclusively on the synaptic vesicle membrane (40). Later, extrarenal expression has been reported in several tissues and cell lines, including pancreatic $\beta$ cells, INS1 cells, Min6 cells, brain, etc. In 3T3-L1 adipocytes, biochemical and immunofluorescence microscopy analysis showed that it locates in both diffuse cytosolic and perinuclear membrane compartments (41). We found that SNAPIN was mostly located in the cytoplasm, and we found that SNAPIN presents some diffuse cytosolic staining and is 

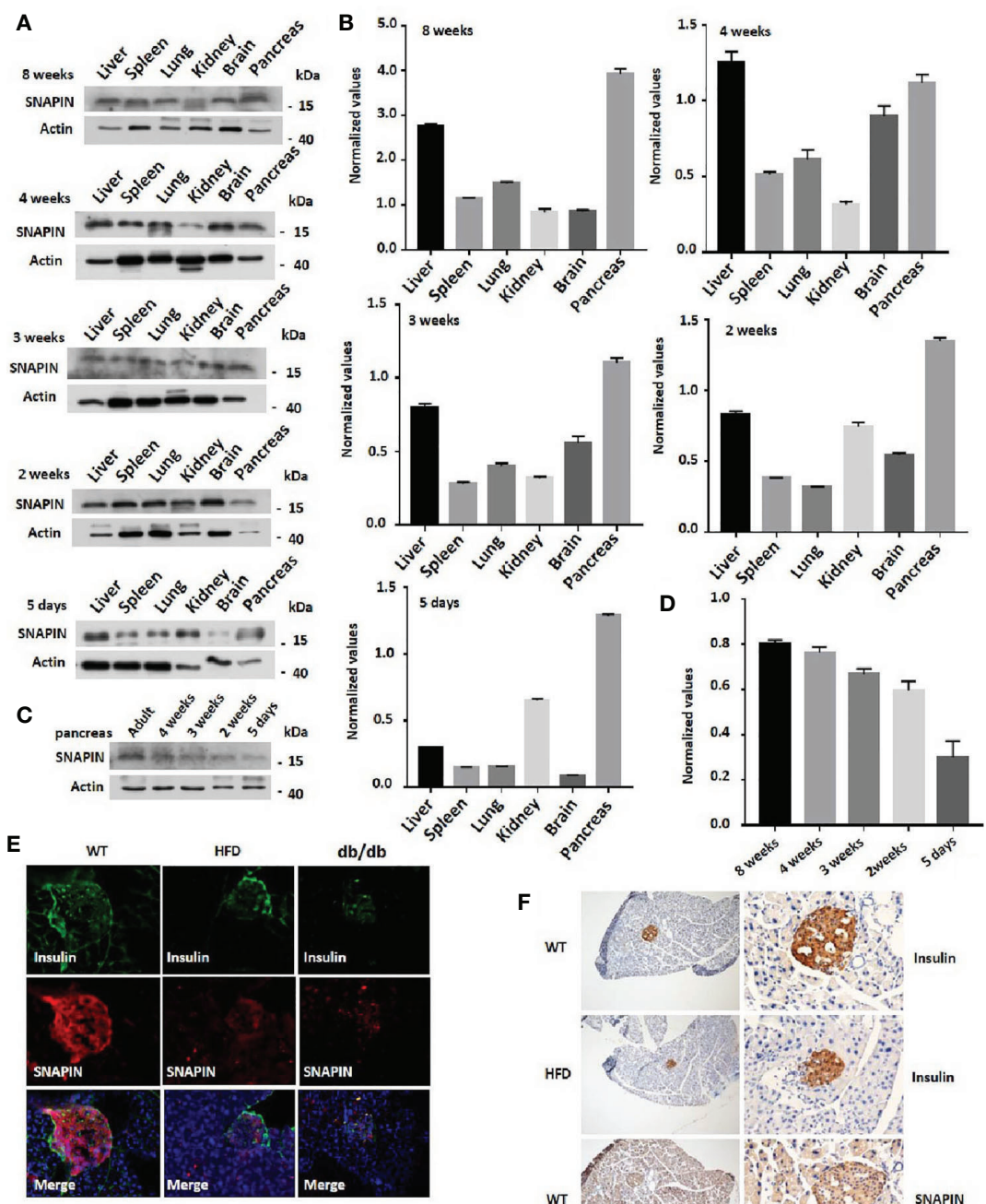

G
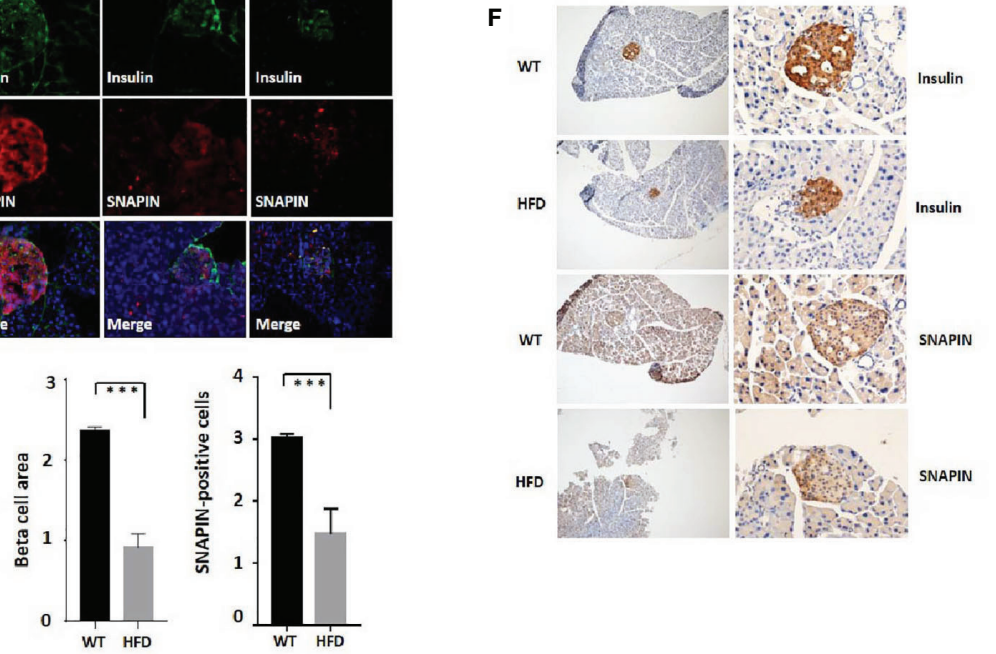

FIGURE 1 | Expression of SNAPIN in mouse tissues. (A) SNAPIN expression was calculated by Western blot. SNAPIN was comparable for 5 days to 8 weeks mouse. (B) Normalized histograms of snapin protein against actin by using imaging software. (C) The expression level of SNAPIN in mouse pancreas also closely increased with the age of mice. (D) Normalized histograms of snapin protein against actin by using imaging software. (E) Representative immunofluorescence images of mouse healthy and pre-diabetic pancreases using antibodies against SNAPIN and insulin. The insulin and SNAPIN of HFD mice and db/db mice were significantly lower than those of wildtype mice. (F) Pancreatic $\beta$ cell size and SNAPIN expression were calculated from the immunohistochemistry (IHC) sections processed for insulin and SNAPIN by capturing bright field images (Leica CTR 4000 series). The $\beta$ cell size of high-fat diet (HFD) mice were significantly smaller than that of wildtype mice, and SNAPIN expression of HFD mice were significantly lower than that of wildtype mice. Scale bar: $100 \mu m$ (left) and $50 \mu m$ (right). Values are expressed as means \pm S.E.M. $P<0.001$ versus control. (G) Statistics for $\beta$ cell size and SNAPIN expression. ${ }^{\star \star \star} P<0.001$.

clustered into punctate structures within the cell body of in rat INS1 cells and Min6 cells. Furthermore, the punctate staining pattern was similar to that seen for insulin-containing secretory granules. The two fields were then superimposed (Figure 2A). And fluorescence co-localization analysis showed that SNAPIN and insulin had a co-localization relationship by ImageJ (Figure 2B). Data analysis confirmed that there was significant cofluorescence between the punctate insulin and SNAPIN signals, which indicates the co-localization of SNAPIN and insulin secretory granules. We also use a wildtype Min6 cell to detect 
A

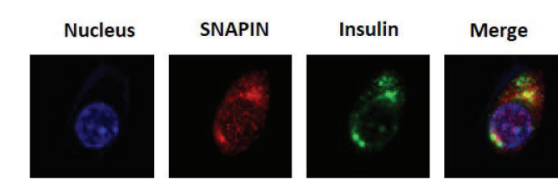

C

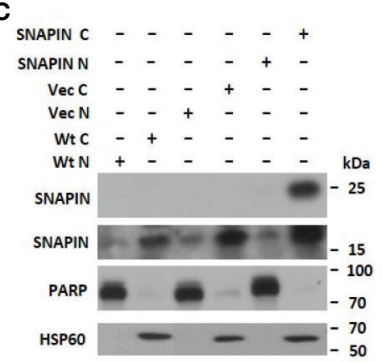

B

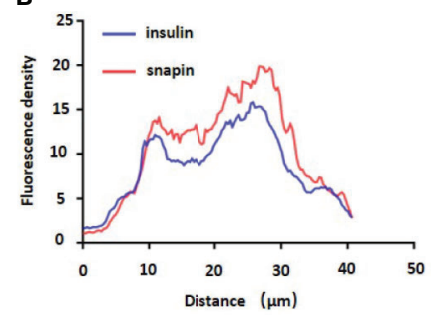

FIGURE 2 | Subcellular localization of SNAPIN. (A). Immunofluorescence was performed to measure the subcellular localization of SNAPIN. SNAPIN was visualized in INS-1 and Min6 cells using anti- SNAPIN antibody in conjunction with anti-rabbit FITC, whereas insulin was visualized using anti-insulin and red-conjugated goat antimouse. Slides were mounted and fluorescence viewed under a laser scanning confocal microscope equipped with a $488 \mathrm{~nm}$ laser excitation filter for FITC. The nuclei were labeled with DAPI (blue) (4',6-diamidino-2-phenylindole), and SNAPIN protein was labeled with the Alesa Fluor 643 (red). Scale bar, 2 mm. (B) The fluorescence distribution of SNAPIN and insulin was analyzed by ImageJ. (C) Nucleocytoplasmic separation was performed to measure the Subcellular localization of SNAPIN. PARP is the nuclear marker, and HSP60 is the cytoplasmic marker. SNAPIN is mainly located in the cytoplasm.

the subcellular localization of SNAPIN and found that nucleocytoplasmic separation showed that SNAPIN was predominantly located in cytoplasm (Figure 2C).

\section{SNAPIN and Its Interacting Protein- Enriched Cell Cycle}

SNAPIN is mostly located in the cytoplasm, and to elucidate the role of SNAPIN in the development and progression of diabetes, a schematic outline of the immunoprecipitation mass spectrometry procedure was used in this study. Flag- SNAPIN or empty vector was overexpressed in Min6 cells and immunoprecipitated using whole cell lysates in triplicates. Min6 cells expressing empty vector alone served as negative controls. To identify putative biological processes associated with SNAPIN interacting proteins, we performed enrichment analysis in the Gene Ontology (GO) domain "Biological Process" (Figure 3A) and KEGG pathway (Figure 3B). This analysis identified cell cycle which related to cell growth.

Immunoblot analysis of the immunoprecipitated fractions showed that tagged- SNAPIN was enriched in the pulldown (Figure 3C). In contrast, no SNAPIN was detected in the pulldown in the vector control. Some papers have previously demonstrated that SNAPIN associates with Bloc1s1 by immunoblot (42). As expected, Bloc1s1 was detected in the current IP-MS study (Figure 3C). These data demonstrate that tagged-SNAPIN can be efficiently and specifically immunoprecipitated from cell extracts.

Proteins significantly interacting with SNAPIN were classified into different protein complexes. The results of this analysis identified twenty predominant complexes:(1) Nop56p-associated pre-rRNA complex, (2) Large Drosha complex, (3) CCT complex (chaperonin containing TCP1 complex), (4) SNW1 complex, (5) PA700 complex, (6) C complex spliceosome, (7) CDC5L complex, (8) TNF-alpha/NF-Kappa B signaling complex and other known complexes: BLOC1 (biogenesis of lysosome-related organelles complex1) complex and Arp2/3 protein complex (Figure 3D).

Our experiments showed that SNAPIN could affect cell proliferation and cell cycle, and we analyzed the cell cycle pathway, which are closely related to cell growth (Figure 3E).

\section{SNAPIN Overexpression Induces Proliferation of $\beta$ Cells}

SNAPIN and its interacting proteins may enrich the cell cycle pathway, which could lead to increased cellular proliferation. To directly evaluate the role of SNAPIN in $\beta$ cell proliferation, we transfected Min6 cells with lentivirus for $24 \mathrm{hrs}$. MTS analysis was applied to detect the cell proliferation. We observed a significant increase in SNAPIN protein abundance in lentivirus-treated Min6 cells by Western blot analysis (Figure 4A). SNAPIN overexpression induced $\beta$ cell proliferation (Figure 4B) and increased Min 6 cells clone formation compared to that control group (Figure 4C). Figure 4D shows the clone statistics.

Our MS data showed an enrichment in SNAPIN and its interacting proteins that are known to regulate the cell cycle. To provide direct evidence that SNAPIN regulates the cell cycle, we transfected Min6 cells with lentivirus to quantified cellular DNA content by flow cytometry (Figure 4E). Compared to the control group, SNAPIN overexpression resulted in an increase in the population of cells in the S phase from $6.85 \%$ to $27.13 \%$. We evaluated $\beta$ cells for expression of CDK2, CDK 4 and CCND1, which mark the $S$ phase of the cell cycle. CDK2, CDK4 and 


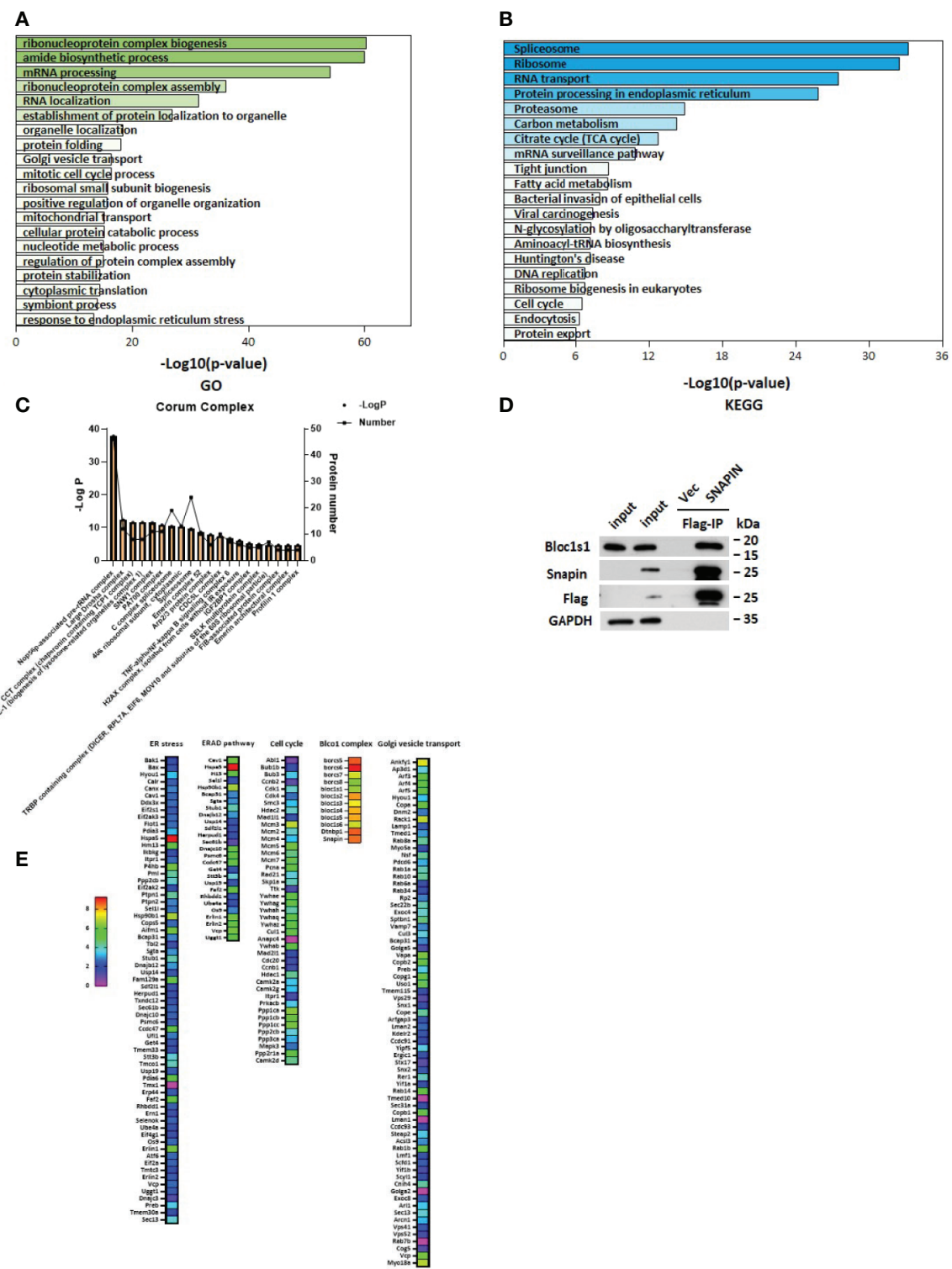

FIGURE 3 | Outputs of proteomic analysis for SNAPIN -altered proteins. Identity of the SNAPIN -binding proteins. Experimental workflow of the identification of the SNAPIN -interacting proteins. Min6 cells were transduced with SNAPIN with specific sequences containing the 3xFlag tag. The resulting cell lysate was reacted with flag beads. The bound fraction was eluted and submitted for shotgun LC-MS/MS. (A, B) Pathways were enriched for common genes by employing the Database for Annotation, Visualization and Integrated Discovery (DAVID) ver. 6.8, KEGG pathway and GO pathway that represent functional classes of SNAPIN interacting proteins. (C) Proteins significantly interacting with SNAPIN were classified into different protein complexes. (D) IP was performed to measure the efficiency of Flag pulldown. BLOCS1 was the positive control. (E) The SNAPIN - binding proteins were identified by Flag Immunoprecipitation pulldown. The heat map shows the score sequest $\mathrm{HT}$, where the intensities in blue indicate the relative abundance of the protein in the sample.

CCND1 expressions were all upregulated (Figures 4F, G). Our results suggested that SNAPIN overexpression could promote the cell proliferation of $\beta$ cells.

\section{SNAPIN Knockdown Inhibit Proliferation of $\beta$ Cells}

Lentivirus shRNA to silence SNAPIN and transfected Min6 cells with lentivirus for 24 hrs. MTS analysis was applied to detect the cell variety. We observed a significant decrease in SNAPIN protein abundance in lentivirus-treated Min6 cells by Western blot analysis (Figure 5A). SNAPIN knockdown inhibited $\beta$ cells proliferation (Figure 5B) and inhibited Min6 cells clone formation compared to that of the control group (Figure 5E). Figure 5F shows the clone statistics. Cell photographic also showed that SNAPIN knockdown could cause Min6 cell death (Figure 5G).

We also quantified cellular DNA content by flow cytometry (Figure 5H). Compared to control group, SNAPIN knockdown 


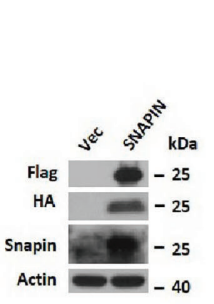

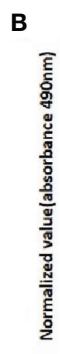

C

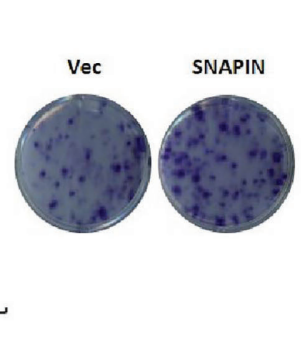

D

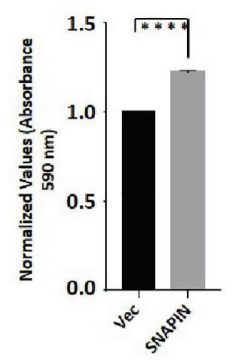

E
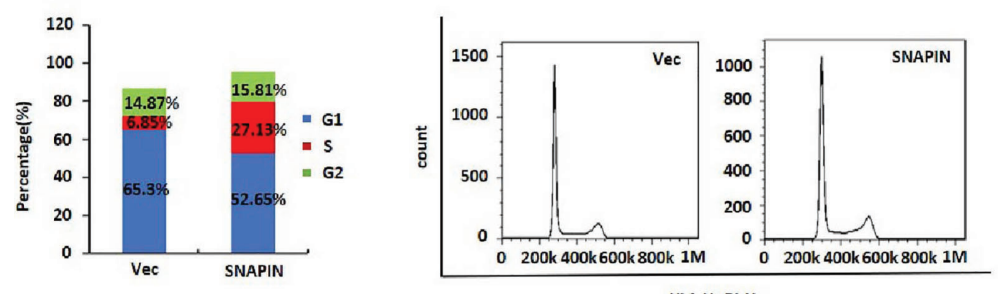

YL1-H::PI-H

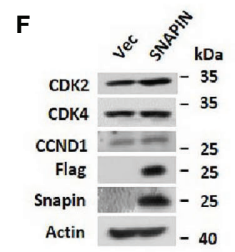

G

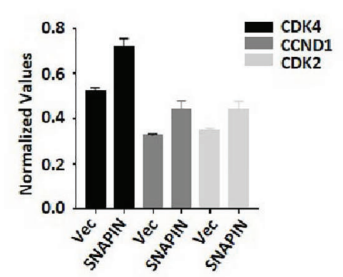

FIGURE 4 | SNAPIN overexpression induces proliferation of $\beta$ cells. Min6 cells were transduced with non-specific and SNAPIN specific Sequences. (A) Min6 cells were treated with lentivirus. A significant increase in SNAPIN protein by Western blot analysis. (B) MTS analysis illustrated the proliferation of Min6 cells induced after SNAPIN overexpression. (C, D) Clone formation showed that SNAPIN overexpression induced the proliferation of $\beta$ cells. (E) The cells were stained with PI staining. Adherent cells were collected, and cell cycle analysis was done by flow cytometry. SNAPIN overexpression increased the population of cells in the $\mathbf{S}$ phase. (F) The protein expression levels of CyclinD1, CDK2 and CDK4 were checked by Western blot with indicated antibodies. (G) Normalized histograms of snapin protein against actin by using imaging software. ${ }^{*} P<0.05,{ }^{* *} P<0.01$, ${ }^{\star \star \star \star} P<0.0001$.

resulted in a decrease in the population of cells in the $S$ phase from $47 \%$ to $40 \%$ and $42.25 \%$. We evaluated $\beta$ cells for expression of CDK2, CDK4 and CCND1, which marks the G1/ $\mathrm{S}$ phase of the cell cycle. CDK2, CDK4 and CCND1 expressions were downregulated (Figures 5I, J). Click-iT ${ }^{\mathrm{TM}} \mathrm{EdU}$ Proliferation Assay measure $\beta$ cells proliferation (Figure 5C). statistics for fluorescence intensity in $585 \mathrm{~nm}$ (Figure 5D). Our results suggested that SNAPIN knockdown could inhibit the proliferation of $\beta$ cells.

\section{SNAPIN Knockdown Induce $\beta$ Cells Apoptosis}

Apoptosis is a specific mode of programmed cell death (43). Inappropriate apoptosis can cause a variety of diseases, so the regulation of apoptosis has great therapeutic potential (44). As a substrate of Caspase 3, PARP cleaves during the initiation of apoptosis program (45). So Cleaved PARP is a signature protein for apoptosis. In order to study the effect of SNAPIN on apoptosis of $\beta$ cells, we used shRNA to interfere with SNAPIN expression and detected cell apoptosis based on Annexin VFITC/PI staining. The proportion of apoptotic cells in the Control group was $10.32 \%$, and the proportion of apoptotic cells after SNAPIN interference was 50.1\% (Figures 6A, B). This result indicated that interference with SNAPIN expression induced apoptosis of cells. we also analyzed the expression level of PARP and SNAPIN (Figures 6C, D).

\section{SNAPIN Knockdown Inhibit Insulin Protein/mRNA Level}

In order to evaluate the effect of SNAPIN on insulin mRNA level, we used shRNA to silence SNAPIN and transfected Min6 cells with lentivirus for $24 \mathrm{hrs}$. We observed a significant decrease in SNAPIN mRNA abundance in lentivirus treated Min6 cells by QPCR analysis (Figure 7A). Insulin- obtained INS1 and INS2 were inhibited after SNAPIN knockdown (Figures 7B, C). We also transfected Min6 cells with lentivirus to quantify insulin mRNA level. 


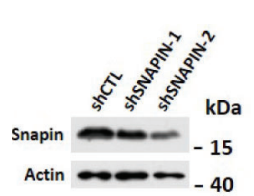

B

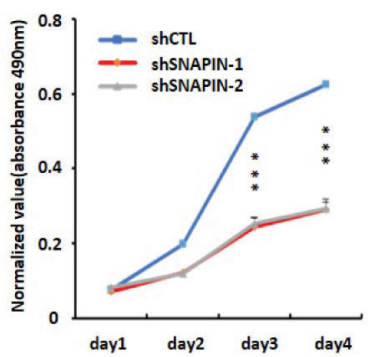

D

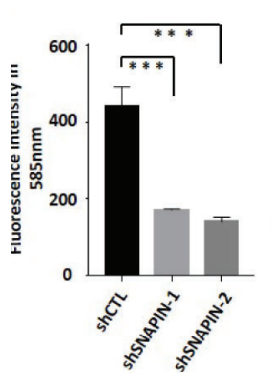

E

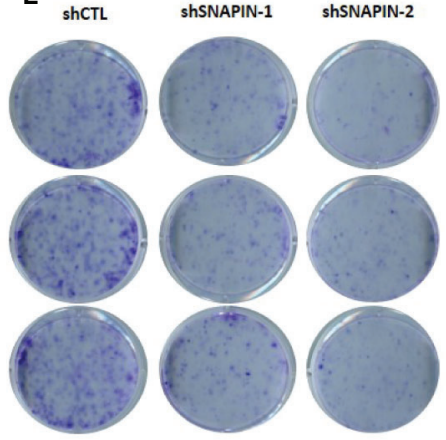

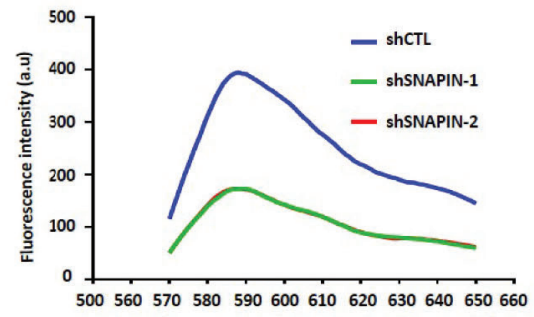

F

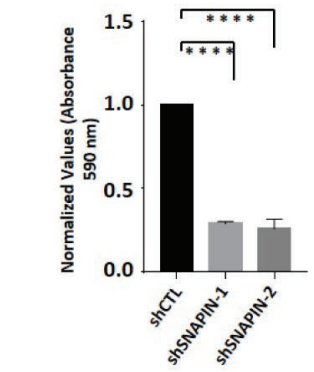

G

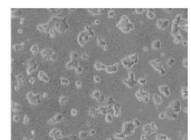

shctL
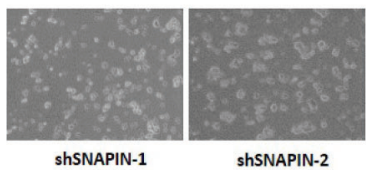

ShSNAPIN-2
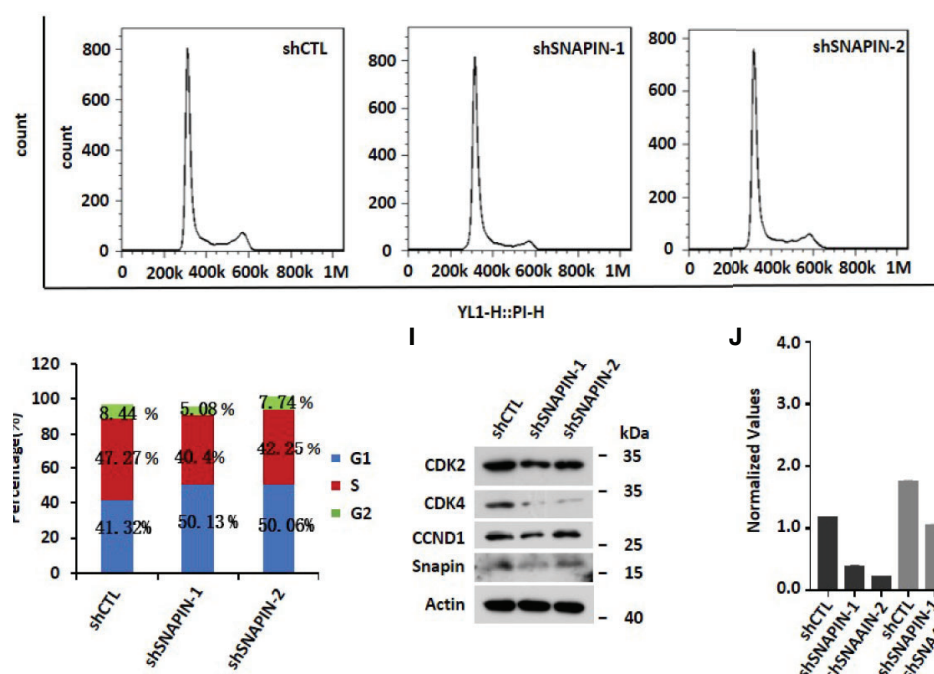

\section{I}

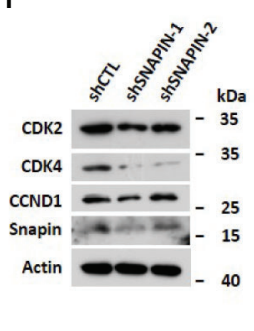

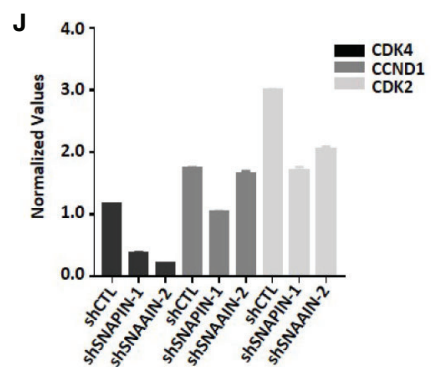

FIGURE 5 | SNAPIN knockdown inhibit proliferation of $\beta$ cells. (A) Mouse Min6 cells were transduced with lentivirus expressing shRNA and non-specific sequences. A significant decrease in SNAPIN protein by Western blot analysis. (B) MTS analysis illustrated that the proliferation of Min6 cells were inhibited after SNAPIN knockdown. (C) Click-iT ${ }^{\mathrm{TM}}$ EdU Proliferation Assay illustrated that the proliferation of Min6 cells were inhibited after SNAPIN knockdown. (D) Statistic for fluorescence intensity in 585nm. (E) Clone formation showed that SNAPIN knockdown inhibited the proliferation of $\beta$ cells. (F) Statistic for clone formation. (G) Cell photography indicates Min6 cells suffer death with SNAPIN knockdown. (H) The cells were stained with PI staining. Adherent cells were collected, and cell cycle analysis was done by flow cytometry. SNAPIN knockdown resulted in a decrease in the population of cells in S phase. (I) The protein expression levels of CyclinD1, CDK2 and CDK4 were checked by Western blot with indicated antibodies. (J) Normalized histograms of snapin protein against actin by using imaging software. ${ }^{\star} \mathrm{P}<0.05,{ }^{* *} \mathrm{P}<0.01,{ }^{* \star *} \mathrm{P}<0.001,{ }^{\star \star \star *} \mathrm{P}<0.0001$. 

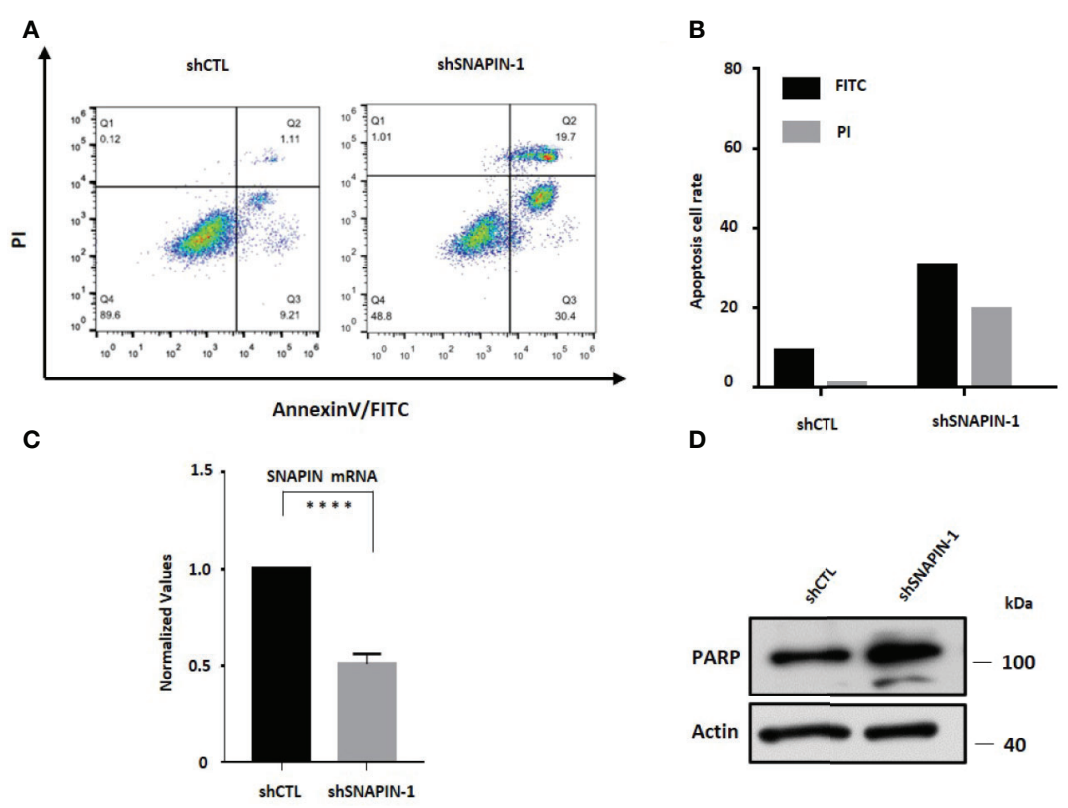

FIGURE 6 | SNAPIN knockdown induce apoptosis of $\beta$ cells. (A) apoptosis assay indicate that the apoptosis of $\beta$ cells were induced after SNAPIN knockdown. (B) statistic for FITC and PI of apoptotic $\beta$ cells. (C) Mouse Min6 cells were transduced with lentivirus expressing shRNA and non-specific sequences. A significant decrease in SNAPIN expression. (D) SNAPIN knockdown induced PARP cleavage of apoptotic marker protein. ${ }^{\star \star \star *} P<0.0001$.

We observed an increase in SNAPIN mRNA abundance in lentivirus treated Min6 cells by QPCR analysis (Figure 7D), and insulin only showed a slight increase (Figures 7E, F).

Min6 cells were treated with two shRNA to interfere SNAPIN. Glucose-induced insulin secretion was measured by ELISA. Min6 cells were stimulated with $2.8 \mathrm{mmol} / \mathrm{L}$ and $16.7 \mathrm{mmol} / \mathrm{L}$ glucose solutions for $2 \mathrm{hr}$, and the supernatant was collected to detect insulin content. After SNAPIN interference, insulin expression was reduced (Figure 7G). Then, we treated INS1 cells with two shRNA to interfere SNAPIN and detected insulin by immunofluorescence. SNAPIN was visualized by GFP, and insulin was visualized using anti-insulin antibody in conjunction with goat anti-mouse cy3. Insulin secretion decreased when SNAPIN was knocked down (Figure $\mathbf{7 H}$ ).

\section{DISCUSSION}

Diabetes mellitus is a very common metabolic disease, its acute and chronic complications have serious impacts on human health (46). Pancreatic $\beta$ cells are the only cells that can produce insulin in the human body. Once the $\beta$ cells are dysfunctional, the body cannot produce enough insulin to maintain the stability of blood glucose, and long-term hyperglycemia of the body will cause multiple organ dysfunction (47). The replication rate of $\beta$ cells is very low, and scientists have attempted to induce the differentiation of $\beta$ cells from progenitor cells or stem cells or from other islet cell lines, but the clinical progress is still very difficult. Many scientists are trying to identify small molecules or biomacromolecules that can induce $\beta$ cells to self-replicate. However, there is no effective drug that can effectively induce $\beta$ cells to replicate. Therefore, it is significant to find new therapeutic targets and new therapeutic methods for diabetes.

SNAPIN was originally reported to be a SNAP25-related protein that mainly interacts with SNARE complexes for vesicle transport to regulate insulin secretion (29). We compared the amino acid sequences of SNAPIN in humans, mice, and rats, and SNAPIN is highly conserved and homologous, suggesting that SNAPIN performs highly consistent biological functions in humans, mice and rats. We extracted various tissues of mice at different ages. SNAPIN was abundant in the pancreas, and its expression increases with the aging of mice, which may indicate that SNAPIN is related to the development of the pancreas. However, more experiments are needed to confirm this, we can extract the islets of mice of different gestational ages to interfere with or overexpress SNAPIN to explore the function of SNAPIN in the development of islets. SNAPIN is significantly correlated with the TMEM27 gene, which encodes a membrane protein that is cleaved and shed by pancreatic $\beta$ cells, and this protein has been proposed as a biomarker for $\beta$ cell quality (33). This suggests SNAPIN may also be a biomarker for $\beta$ cells.

Furthermore, we used SNAPIN as bait to find SNAPIN interacting proteins and various protein complexes were enriched, including BLOC1, BORC, Arp2/3, Dynactin Complex.Snap23, Snap47 and other SNAP family members reported in the paper that interact with SNAPIN. We verify our results by using Bloc1s1 as a positive control. The proteins with high ratings were analyzed by Metascope and further enriched by BO/KEGG pathway. We enriched BLOC1/BORC, 


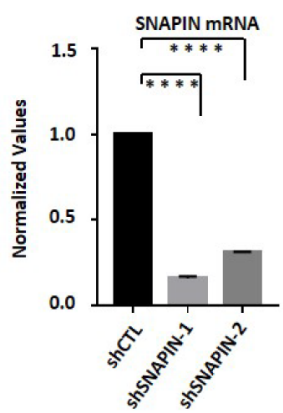

D

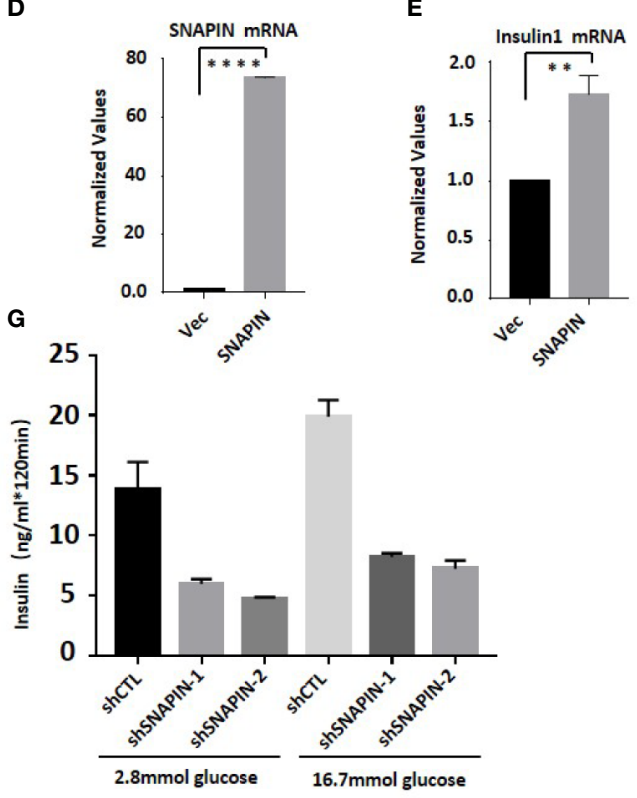

B

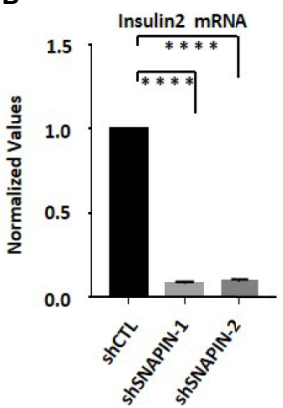

C

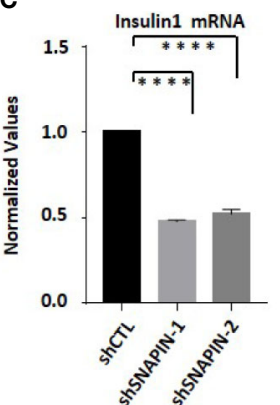

$\mathbf{F}$

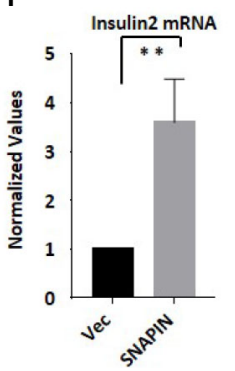

H Nuclear GFP Insulin

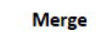

Nuclear
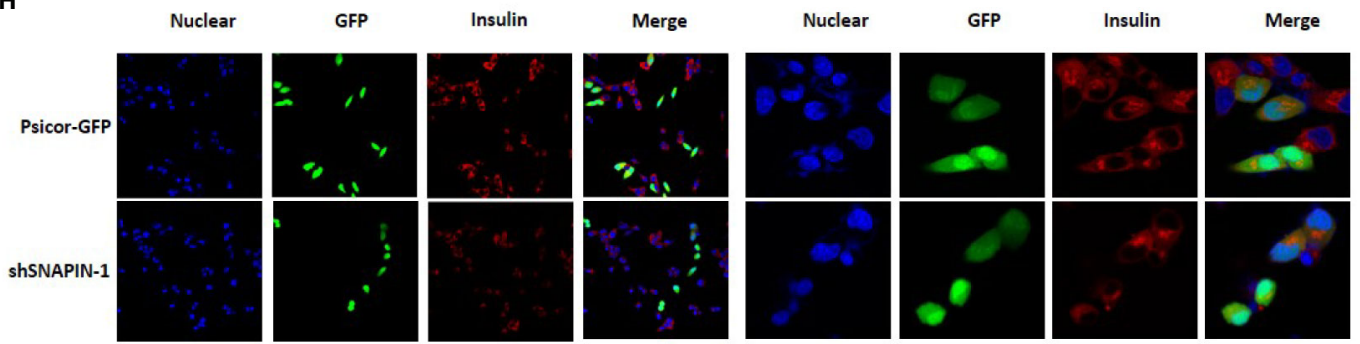

shSNAPIN-2
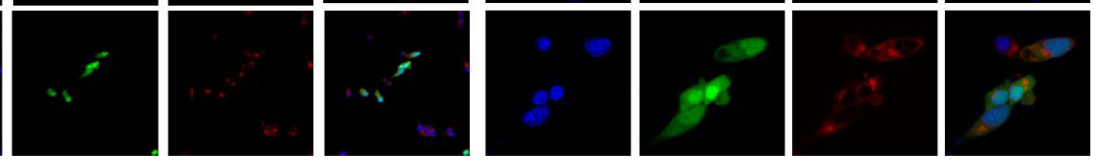

FIGURE 7 | SNAPIN affects insulin mRNA and protein levels. (A) SNAPIN knockdown efficiency in $\beta$ cells. (B, C) SNAPIN knockdown inhibit Insulin mRNA expression in $\beta$ cells. (D) SNAPIN overexpression efficiency in $\beta$ cells. (E, F) SNAPIN overexpression increased Insulin mRNA expression in $\beta$ cells. QPCR was performed to measure the mRNA expression of insulin. Data are shown as the mean $\pm S D, n=3$. (G) SNAPIN knockdown inhibits insulin protein expression in INS1 cells. Glucose-induced insulin secretion measured by ELISA. (H) SNAPIN knockdown inhibits insulin protein expression in Min6 cells. INS1 cells were transduced with lentivirus expressing shRNA which obtained GFP. The vector was Psicor-GFP. The insulin protein expression levels were measured by immunofluorescence. The nuclei were labeled with DAPI (blue) (4,6-diamidino-2-phenylindole), insulin protein was labeled with the Alesa Fluor 643 (red) and shSNAPIN was labeled with the GFP (yellowish-green). ${ }^{\star \star} P<0.01,{ }^{\star \star \star \star} P<0.0001$. 
which is a SNAPIN family member, and cell cycle and protein processing in the endoplasmic reticulum etc, can further explore the mechanism. According to KEGG enrichment results, we detected changes in major proteins in the UPR pathway. Our experiment results show that SNAPIN affects the Min6 cell cycle and the level of cell cycle markers. We will continue to explore whether SNAPIN regulates $\beta$ cell proliferation by interacting with cell cycle-related protein in follow-up work.

As the only glucose-lowering hormone in the body, insulin can also promote body growth (48). Our study shows that SNAPIN can promote insulin secretion, which is consistent with other reports (25). We found that SNAPIN promotes $\beta$ cell growth, and it remains to be seen whether this pro-growth effect is due to SNAPIN or due to the increase in insulin secretion.

In conclusion, we showed that overexpression of SNAPIN is sufficient to induce $\beta$ cell proliferation. We can therefore try to design agonists for the SNAPIN sequence as a new treatment for diabetes. This is a huge challenge but could provide new strategies for treating diabetes. Taking a broader perspective, SNAPIN overexpression promoting cell proliferation may open a new avenue of research in the field of tissue regeneration.

Finally, it is important to emphasize that there are many treatments available in addition to $\mathrm{b}$ cell proliferation. For example, many of the pathways that activate proliferation also activate survival pathways, another important therapeutic objective. Further, $\beta$ cell expansion might be achieved through other approaches, notably $\beta$ cell redifferentiation and trans-differentiation from a- or $\mathrm{d}$-cells to $\beta$ cells $(49,50)$. Of course, creating new $\beta$ cells also requires effectively addressing autoimmunity. These are all critical, fertile and active areas of $\beta$ cell therapeutic research.

\section{DATA AVAILABILITY STATEMENT}

The data presented in the study are deposited in the PRIDE repository, accession number PXD023786.

\section{REFERENCES}

1. Wu X, Liang WW, Guan HY, Liu J, Liu LH, Li H, et al. Exendin-4 Promotes Pancreatic Beta-Cell Proliferation Via Inhibiting the Expression of Wnt5a. Endocrine (2017) 55(2):398-409. doi: 10.1007/s12020-016-1160-x

2. Chen CG, Cohrs CM, Stertmann J, Bozsak R, Speier S. Human Beta Cell Mass and Function in Diabetes: Recent Advances in Knowledge and Technologies to Understand Disease Pathogenesis. Mol Metab (2017) 6(9):943-57. doi: 10.1016/j.molmet.2017.06.019

3. Wang R, Munoz EE, Zhu S, McGrath BC, Cavener DR. Perk Gene Dosage Regulates Glucose Homeostasis by Modulating Pancreatic Beta-Cell Functions. PloS One (2014) 9(6):e99684. doi: 10.1371/journal.pone. 0099684

4. Mondal P, Prasad A, Girdhar K. Interventions to Improve Beta-Cell Mass and Function. Ann Endocrinol (Paris) (2017) 78(5):469-77. doi: 10.1016/ j.ando.2016.11.002

5. Wang P, Alvarez-Perez J-C, Felsenfeld DP. Induction of Human Pancreatic Beta Cell Replication by Inhibitors of Dual Specificity Tyrosine Regulated Kinase. Nat Med (2015) 21:383-8. doi: 10.1038/nm.3820

6. Cnop M, Welsh N, Jonas J-C. Mechanisms of Pancreatic-Cell Death in Type 1 and Type 2 Diabetes. Diabetes (2005) 54:S97-S107. doi: 10.2337/ diabetes.54.suppl_2.S97

\section{ETHICS STATEMENT}

The animal study was reviewed and approved by Xiamen University Institutional Animal Care and Use Committee. Written informed consent was obtained from the owners for the participation of their animals in this study.

\section{AUTHOR CONTRIBUTIONS}

MJ designed and performed experiments, analyzed data and drafted the manuscript. ZK designed and performed experiments and analyzed data. WW, WL, and JC conceived and designed the experiments, analyzed and interpreted data, and revised the manuscript. All authors read and approved the manuscript. All authors contributed to the article and approved the submitted version.

\section{FUNDING}

This work was supported by grants from the Natural Science Foundation of China (81471081 to WW, 91953114, $81761128015,81861130370,31871319$ to $\mathrm{WL}$ ), the Natural Science Foundation of Fujian Province, China (2019J01010 to WW), Xiamen Research Foundation for Science and Technology Project (3502Z20194037 to WW) and Scientific Research Foundation for Advanced Talents, Xiang'an Hospital of Xiamen University (PM201809170005 to WW).

\section{ACKNOWLEDGMENTS}

The authors thank Ming Yu Li for the technical assistance $\mathrm{db} / \mathrm{db}$ mice and HFD mice in this study. Psicor-GFP plasmid was a gift from Tuan Lao Wang.

7. Kahn SE, Hull RL, Utzschneider KM. Mechanisms Linking Obesity to Insulin Resistance and Type 2 Diabetes. Nature (2006) 444:840-6. doi: 10.1038/ nature 05482

8. Rieck S, Kaestner KH. Expansion of Beta-Cell Mass in Response to Pregnancy. Trends Endocrinol Metab (2010) 21(3):151-8. doi: 10.1016/ j.tem.2009.11.001

9. Simmons RA, Templeton L, Niu H. Intrauterine Growth Retardation in the Rat Leads to Reduced Proliferation and Increased Apoptosis of the B-Cell. Pediatr Res (1999) 45(4):62a-a. doi: 10.1203/00006450-199904020-00374

10. Dadon D, Tornovsky-Babaey S, Furth-Lavi J, Ben-Zvi D, Ziv O, Schyr-BenHaroush R. Glucose Metabolism: Key Endogenous Regulator of $\beta$-Cell Replication and Survival. Diabetes Obes Metab (2012) 14:101-8. doi: 10.1111/j.1463-1326.2012.01646.x

11. Stolovich-Rain M, Hija A, Grimsby J, Glaser B, Dor Y. Pancreatic Beta Cells in Very Old Mice Retain Capacity for Compensatory Proliferation. J Biol Chem (2012) 287(33):27407-14. doi: 10.1074/jbc.M112.350736

12. Yamamoto J, Imai J, Izumi T, Takahashi H, Kawana Y. Neuronal Signals Regulate Obesity Induced $\beta$-Cell Proliferation by FoxM1 Dependent Mechanism. Nat Commun (2017) 8:1930. doi: 10.1038/s41467-017-01869-7

13. Maehra R, Chena S, Snitowa M. Generation of Pluripotent Stem Cells From Patients With Type 1 Diabetes. PNAS (2009) 106:15768-73. doi: 10.1073/ pnas.0906894106 
14. Lu B, Munoz-Gomez M, Ikeda Y. The Two Major Glucokinase Isoforms Show Conserved Functionality in $\beta$-Cells Despite Different Subcellular Distribution. Biol Chem (2018) 399(6):565-576. doi: 10.1515/hsz-2018-0109

15. Metukuri MR, Zhang P, Basantani MK. ChREBP Mediates GlucoseStimulated Pancreatic Beta-Cell Proliferation. Diabetes (2012) 61(8):200415. doi: $10.2337 / \mathrm{db} 11-0802$

16. Dai C, Hang Y, Shostak A. Age-Dependent Human Beta Cell Proliferation Induced by Glucagon-Like Peptide 1 and Calcineurin Signaling. J Clin Invest (2017) 127(10):3835-44. doi: 10.1172/JCI91761

17. Stewart nF, Hussain MA, García-Ocaña XXXA. Human $\beta$-Cell Proliferation and Intracellular Signaling: Part 3. Diabetes (2015) 64(6):1872-85. doi: $10.2337 / \mathrm{db} 14-1843$

18. Tiwari S, Roel C, Wills R, Casinelli G, Tanwir M, Takane KK, et al. Early and Late G1/s Cyclins and Cdks Act Complementarily to Enhance Authentic Human Beta-Cell Proliferation and Expansion. Diabetes (2015) 64(10):348598. doi: $10.2337 / \mathrm{db} 14-1885$

19. Nguyen-Tu MS, da Silva Xavier G, Leclerc I, Rutter GA. Transcription factor7-like 2 (TCF7L2) Gene Acts Downstream of the Lkb1/Stk11 Kinase to Control mTOR Signaling, Beta Cell Growth, and Insulin Secretion. J Biol Chem (2018) 293(36):14178-89. doi: 10.1074/jbc.RA118.003613

20. Ilardi JM, Mochida S, Sheng Z-H. Snapin: A SNARE-Associated Protein Implicated in Synaptic Transmission. Nat Neurosci (1999) 2:119-24. doi: $10.1038 / 5673$

21. Pu J, Schindler C, Jia R. BORC, a Multisubunit Complex That Regulates Lysosome Positioning. Dev Cell (2015) 33(2):176-88. doi: 10.1016/j.devcel.2015.02.011

22. Hartwig C, Monis WJ, Chen X. Neurodevelopmental Disease Mechanisms, Primary Cilia, and Endosomes Converge on the BLOC-1 and BORC Complexes. Dev Neurobiol (2018) 78(3):311-30. doi: 10.1002/dneu.22542

23. Zhou B, Cai Q, Xie Y, Sheng Z-H. Snapin Recruits Dynein to BDNF-TrkB Signaling Endosomes for Retrograde Axonal Transport and Is Essential for Dendrite Growth of Cortical Neurons. Cell Rep (2012) 2(1):42-51. doi: 10.1016/j.celrep.2012.06.010

24. Zhou B, Zhu Y-B, Lin L, Cai Q, Sheng Z-H. Snapin Deficiency is Associated With Developmental Defects of the Central Nervous System. Biosci Rep (2011) 31(2):151-8. doi: 10.1042/BSR20100110

25. Song WJ, Seshadri M, Ashraf U, Mdluli T, Mondal P, Keil M, et al. Snapin Mediates Incretin Action and Augments Glucose-Dependent Insulin Secretion. Cell Metab (2011) 13(3):308-19. doi: 10.1016/j.cmet.2011.02.002

26. Langemeyer L, Ungermann C. BORC and BLOC-1: Shared Subunits in Trafficking Complexes. Dev Cell (2015) 33(2):121-2. doi: 10.1016/ j.devcel.2015.04.008

27. Somanath S, Partridge CJ, Marshall C. Snapin Mediates Insulin Secretory Granule Docking, But Not Trans-SNARE Complex Formation. Biochem Biophys Res Commun (2016) 473(2):403-7. doi: 10.1016/j.bbrc.2016.02.123

28. Yu SC, Klosterman SM, Martin AA, Gracheva EO, Richmond JE. Differential Roles for Snapin and Synaptotagmin in the Synaptic Vesicle Cycle. PloS One (2013) 8(2):e57842. doi: 10.1371/journal.pone.0057842

29. Gaisano HY. Recent New Insights Into the Role of SNARE and Associated Proteins in Insulin Granule Exocytosis. Diabetes Obes Metab (2017) 19:11523. doi: $10.1111 /$ dom. 13001

30. Sudhof TC, Rothman JE. Membrane Fusion: Grappling With SNARE and SM Proteins. Science (2009) 323(5913):474-7. doi: 10.1126/science.1161748

31. Thakur P, Stevens DR, Sheng Z-H, Rettig J. Effects of PKA-mediated Phosphorylation of Snapin on Synaptic Transmission in Cultured Hippocampal Neurons. J Neurosci (2004) 24(29):6476-81. doi: 10.1523/ JNEUROSCI.0590-04.2004

32. Fukui K, Yang Q, Cao Y, Takahashi N. The HNF-1 Target Collectrin Controls Insulin Exocytosis by SNARE Complex Formation. Cell Metab (2005) 2 (6):373-84. doi: 10.1016/j.cmet.2005.11.003

33. Altirriba J, Gasa R, Casas S, Ramirez-Bajo MJ, Ros S, Gutierrez-Dalmau A, et al. The Role of Transmembrane Protein 27 (TMEM27) in Islet Physiology and its Potential Use as a Beta Cell Mass Biomarker. Diabetologia (2010) 53 (7):1406-14. doi: 10.1007/s00125-010-1728-6
34. Gao WW, Xiao RQ, Zhang WJ, Hu YR, Peng BL, Li WJ, et al. Jmjd6 Licenses Eralpha-Dependent Enhancer and Coding Gene Activation by Modulating the Recruitment of the CARM1/MED12 Co-Activator Complex. Mol Cell (2018) 70(2):340-357 e8. doi: 10.1016/j.molcel.2018.03.006

35. Peng BL, Li WJ, Ding JC, He YH, Ran T, Xie BL, et al. A Hypermethylation Strategy Utilized by Enhancer-Bound CARM1 to Promote Estrogen Receptor Alpha-Dependent Transcriptional Activation and Breast Carcinogenesis. Theranostics (2020) 10(8):3451-73. doi: 10.7150/thno.39241

36. C. Gene Ontology. The Gene Ontology (GO) Project in 2006. Nucleic Acids Res (2006) 34(Database issue):D322-6. doi: 10.1093/nar/gkj021

37. Kanehisa M, Furumichi M, Tanabe M, Sato Y, Morishima K. KEGG: New Perspectives on Genomes, Pathways, Diseases and Drugs. Nucleic Acids Res (2017) 45(D1):D353-61. doi: 10.1093/nar/gkw1092

38. Yuan X, Shan Y, Zhao Z, Chen J, Cong Y. Interaction Between Snapin and GCSF Receptor. Cytokine (2006) 33:219e225. doi: 10.1016/j.cyto.2006.01.008

39. Wang G, Ren G, Cui X, Lu Z, Ma Y, Qi Y, et al. Host Protein Snapin Interacts With Human Cytomegalovirus pUL130 and Affects Viral DNA Replication. J Biosci (2016) 41(2):173-82. doi: 10.1007/s12038-016-9604-2

40. Dickman DK, Tong A, Davis GW. Snapin Is Critical for Presynaptic Homeostatic Plasticity. J Neurosci (2012) 32(25):8716-24. doi: 10.1523/ jneurosci.5465-11.2012

41. Buxton P, Zhang XM, Walsh B, Sriratana A, Schenberg I, Manickam E, et al. Identification and Characterization of Snapin as a Ubiquitously Expressed SNARE-Binding Protein That Interacts With SNAP23 in Non-Neuronal Cells. Biochem J (2003) 375:433-40. doi: 10.1042/Bj20030427

42. Starcevic M, Dell'Angelica EC. Identification of Snapin and Three Novel Proteins (BLOS1, BLOS2, and BLOS3/reduced Pigmentation) as Subunits of Biogenesis of Lysosome-Related Organelles Complex-1 (BLOC-1). J Biol Chem (2004) 279(27):28393-401. doi: 10.1074/jbc.M402513200

43. Formigli L, Papucci L, Tani A, Schiavone N, Tempestini A, Orlandini GE, et al. Aponecrosis: Morphological and Biochemical Exploration of a Syncretic Process of Cell Death Sharing Apoptosis and Necrosis. J Cell Physiol (2000) 182(1):41-9. doi: 10.1002/(SICI)1097-4652(200001)182:1<41::AIDJCP5 $>3.0$. CO;2-7

44. Elmore S. Apoptosis: A Review of Programmed Cell Death. Toxicol Pathol (2007) 35(4):495-516. doi: 10.1080/01926230701320337

45. McIlwain DR, Berger T, Mak TW. Caspase Functions in Cell Death and Disease. Cold Spring Harb Perspect Biol (2013) 5(4):a008656. doi: 10.1101/ cshperspect.a008656

46. Cole JB, Florez JC. Genetics of Diabetes Mellitus and Diabetes Complications. Nat Rev Nephrol (2020) 16(7):377-90. doi: 10.1038/s41581-020-0278-5

47. Guthrie RA, Guthrie DW. Pathophysiology of Diabetes Mellitus. Crit Care Nurs Q (2004) 27(2):113-25. doi: 10.1097/00002727-200404000-00003

48. Menon RK, Sperling MA. Insulin as a Growth Factor. Endocrinol Metab Clinics North America (1996) 25(3):633-. doi: 10.1016/S0889-8529(05)70344-3

49. Bensellam M, Jonas JC, Laybutt DR. Mechanisms of Beta-Cell Dedifferentiation in Diabetes: Recent Findings and Future Research Directions. J Endocrinol (2018) 236(2):R109-43. doi: 10.1530/JOE-17-0516

50. Talchai C, Xuan S, Lin HV, Sussel L, Accili D. Pancreatic Beta Cell Dedifferentiation as a Mechanism of Diabetic Beta Cell Failure. Cell (2012) 150(6):1223-34. doi: 10.1016/j.cell.2012.07.029

Conflict of Interest: The authors declare that the research was conducted in the absence of any commercial or financial relationships that could be construed as a potential conflict of interest.

Copyright $\odot 2021$ Jiang, Kuang, He, Cao, Yu, Cheng, Liu and Wang. This is an openaccess article distributed under the terms of the Creative Commons Attribution License (CC BY). The use, distribution or reproduction in other forums is permitted, provided the original author(s) and the copyright owner(s) are credited and that the original publication in this journal is cited, in accordance with accepted academic practice. No use, distribution or reproduction is permitted which does not comply with these terms. 